\title{
O Rio de Janeiro a partir da chegada da Corte Portuguesa: Planos, intenções e intervenções no século XIX
}

\author{
CARVALHO, Amanda Lima dos Santos
}

\begin{abstract}
Resumo
A transferência da Corte Portuguesa para o Brasil em 1808 trouxe consigo novas intenções e planos para o Brasil e para a cidade do Rio de Janeiro. A carente colônia necessitava de um governo organizado e instituições administrativas, de escolas, estradas, bancos, fábricas. Todas as mudanças que ocorreriam na estrutura urbana naquele período teriam como pano de fundo a sua adaptação à função de sede do Império. Nesse processo, afastar-se das características de cidade colonial era imprescindível para o Rio de Janeiro. A pesquisa que deu origem a esse artigo tem como objetivo resgatar, sob o olhar dos planos urbanísticos, dos projetos e das transformações efetuadas no Rio de Janeiro no século XIX, a maneira de pensar a cidade a partir da chegada da corte real, mostrando o quanto esse fato foi fundamental para alterá-la, posteriormente, no início do século XX. Os novos hábitos trazidos da metrópole europeia modificaram o comportamento dos moradores, e a Missão Francesa de 1816, chefiada por Joaquim Lebreton, contribuiu nesse processo. Durante o século XIX foram elaborados dois planos urbanísticos para a cidade do Rio de Janeiro: o Relatório Beaurepaire em 1843 e o Relatório da Comissão de Melhoramentos, em 1875 e 1876. Ambos tinham como preocupação questões de higiene, controle e indução do desenvolvimento da cidade, pavimentação, abertura e alargamento de vias, além de representarem a síntese do pensamento urbanístico do momento. Ao se analisar os planos anteriormente citados, observamos muitos princípios que foram colocados em prática nas grandes intervenções urbanas do século XX.
\end{abstract}

Palavras-chave: Rio de Janeiro. História Urbana. Planos Urbanísticos. Transferência da Corte Portuguesa. Século XIX.

\begin{abstract}
:
This paper attempts to rescue, under the prism of urban plans, projects, and works carried out in Rio de Janeiro in the nineteenth century, the ways of thinking that held sway in the city after the arrival of the Portuguese Court, investigating how this event was fundamental in transforming the city long afterward, in the twentieth century. The transfer of the Court to Brazil in 1808 brought new perspectives and plans to Rio and to the entire country. All the changes that occurred in the urban structure during that period had as their backdrop the city's adaptation to its role as capital of the Empire. In this process, it was essential to overcome the shortcomings of a colonial outpost whose conditions shocked the new arrivals, in counterpoint to its stunning natural beauty. The new customs brought from the European metropolis changed local ones and the French Artistic Mission of 1816, headed by Joaquim Lebreton, contributed to this process. Two plans were prepared for Rio, as the capital of the new Brazilian empire established after obtaining independence from Portugal in 1822: the Beaurepaire Report in 1843 and the Improvement Commission Report in 1875-1876. Both focused on sanitation, control and induction of urban development, pavement of new streets and widening of existing ones, as well as summarized the urbanistic concept of the time. Analyzing these reports reveals many proposals that were put into practice in the great interventions of the twentieth century.
\end{abstract}

Keywords: Rio de Janeiro. Urban History. Urbanistic Plans. Transfer of the Portuguese Court. 19th Century. 


\section{A transferência da família real portuguesa}

A pesquisa que deu origem a este artigo teve como objetivo recuperar, sob o olhar dos planos urbanísticos, dos projetos, intenções e transformações efetuadas no Rio de Janeiro no século XIX, a maneira de pensar a cidade a partir da chegada da corte real, mostrando o quanto esse fato foi fundamental para alterá-la, posteriormente, no início do século XX.

Colônia de Portugal desde o século XVI e capital do vice-reino desde 1763, o Rio de Janeiro teve seu desenvolvimento marcado pela transferência da corte portuguesa em 1808. Desde então, até 1821 , foi sede da monarquia portuguesa, única cidade das Américas na história a receber o aparato burocrático e o contingente populacional antes instalado na Europa. Até então nenhum rei havia visitado seus territórios ultramarinos, nem mesmo para conhecê-los, muito menos para morar e governar.

A fuga da monarquia portuguesa para sua colônia americana por ocasião da invasão dos exércitos napoleônicos é um divisor de águas no processo histórico brasileiro. Os preparativos iniciais para acomodar a família real marcaram apenas o começo da transformação do Rio de Janeiro, pois o projeto de construir uma nova cidade e capital imperial perdurou por todo reinado brasileiro do príncipe regente (SCHULTZ, 2008).

A estrutura urbana encontrada pela família real foi em grande parte construída por Luis de Vasconcelos e Sousa, que administrou a cidade entre os anos de 1778 e 1790. O vice-rei é considerado autor da primeira remodelação urbana do Rio de Janeiro e precursor das intervenções voltadas à adequação da cidade aos conceitos modernos das capitais europeias, atuando não só na expansão da estrutura urbana, mas também nos usos desses espaços. Sua gestão é conhecida principalmente pela construção do Passeio Público e reurbanização do Largo do Carmo, expressões da prosperidade da época.

A transformação do Rio de Janeiro em corte real começou apenas dois meses antes da chegada do príncipe regente, quando as notícias do exílio real foram recebidas. As ações imediatas deveriam dar conta dos novos usos, nova classe, novas necessidades e novos agentes que junto com a corte chegavam ao Brasil.

Menos de uma semana após sua chegada, ainda em Salvador, D. João VI decretou a abertura dos portos às "nações amigas". Esta medida representou um golpe de morte no pacto colonial que, na prática, obrigava que todos os produtos das colônias passassem antes pelas alfândegas em Portugal, ou seja, os demais países não podiam vender produtos para o Brasil, nem importar matérias-primas diretamente das colônias alheias, sendo forçados a fazer negócios com as respectivas metrópoles.

Permitiu assim a integração do Brasil ao mercado mundial e consequente invasão de produtos estrangeiros, rompendo a base sobre a qual se assentava o domínio metropolitano: o monopólio comercial. De acordo com Pinto (2007), essa medida era prova de uma contradição inevitável na política econômica adotada pela Corte, que queria imprimir os princípios do liberalismo econômico em pleno território colonial.

No que diz respeito ao perímetro urbano do Rio de Janeiro, Dom João VI cria o imposto da décima, para os prédios urbanos em condições habitáveis dentro dos limites das cidades e vilas. Prática já conhecida em Portugal, o tributo consistia no pagamento anual para a Real Fazenda, por parte dos proprietários, de $10 \%$ dos

Figura 1: Vista do Largo do Carmo em 1775.

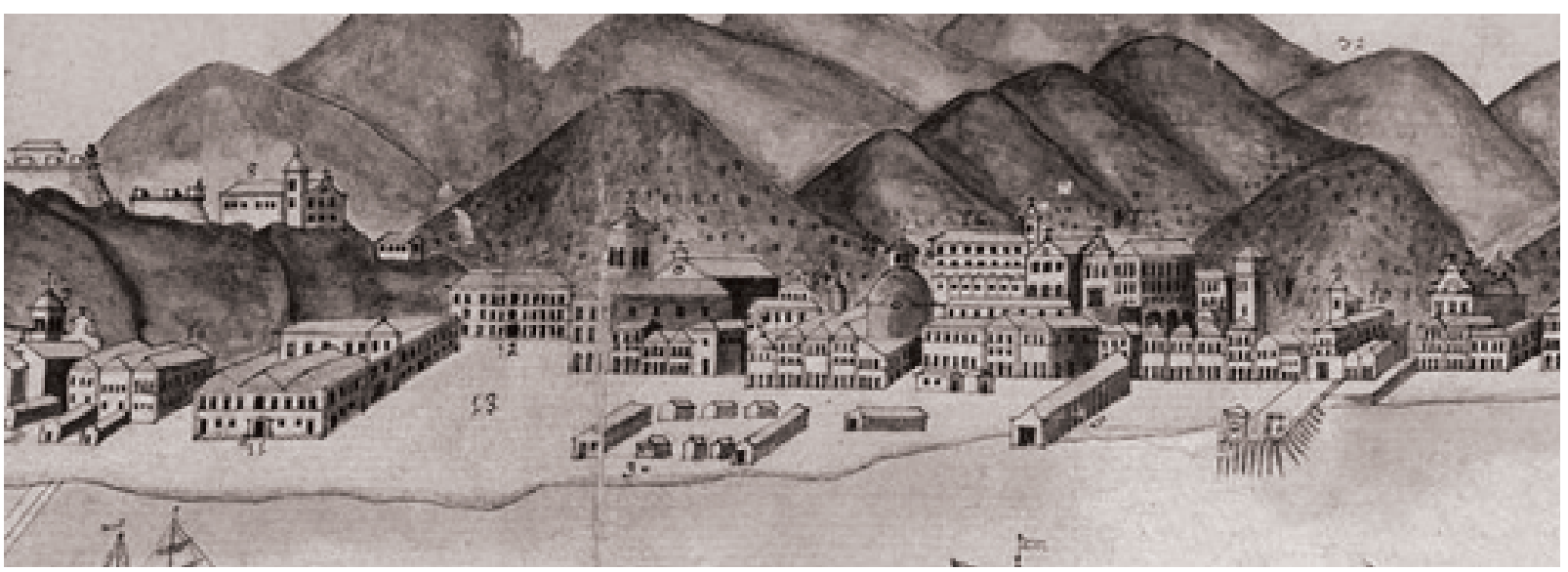

Fonte: Base digital da Biblioteca Nacional. Disponível em: <http://bndigital.bn.br/acervo-digital/>. Acesso em: 16 jul. 2013. 


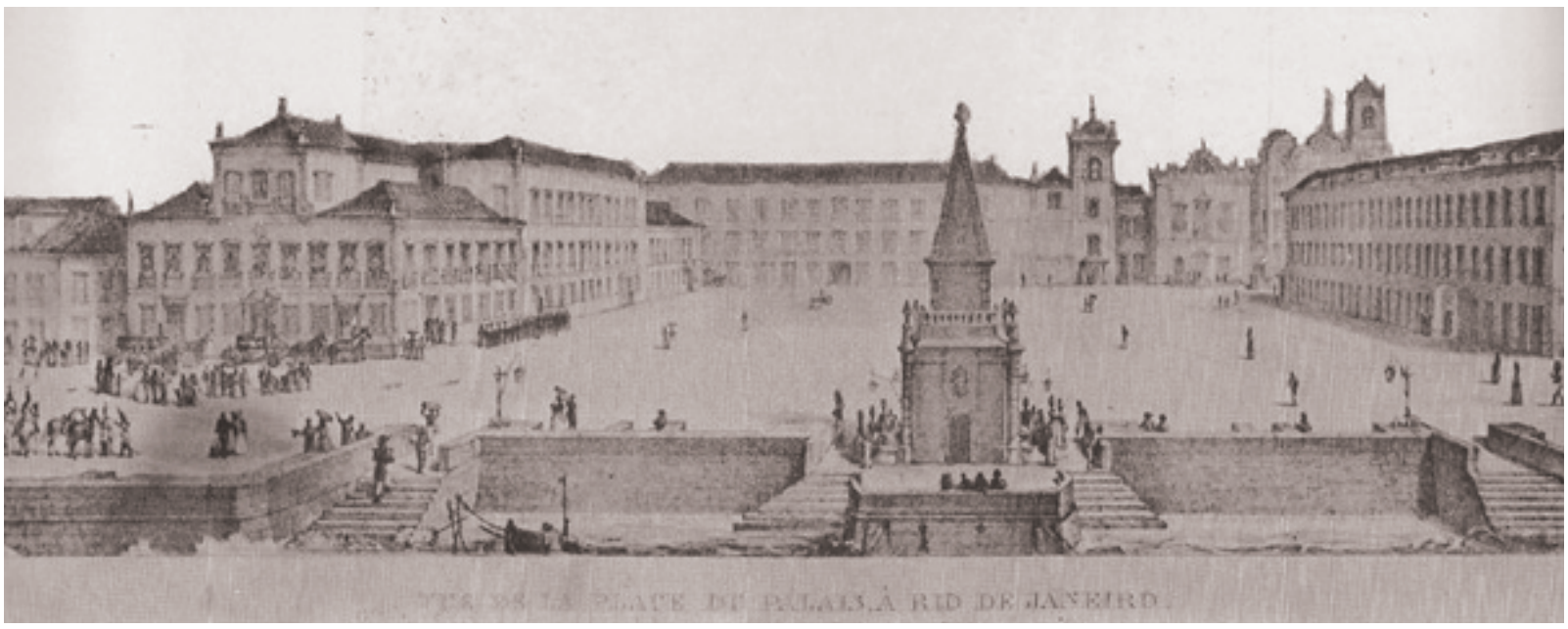

Fonte: PUC, 1979, p. 128.

rendimentos líquidos dos prédios, com o objetivo de suprir os cofres da Corte portuguesa estabelecida no Rio de Janeiro, criando uma fonte de renda imediata.

Silva (2012, p. 52) ressalta que três medidas de impacto devem ser destacadas, que foram colocadas em prática logo na chegada da família real, quando "uma nova forma de organização começava a ser gestada, articulando conhecimento, atuação sobre o espaço urbano e normas". Foram elas: criação da Intendência Geral da Polícia, o diagnóstico médico e o mapa oficial, o qual tinha como objetivo registrar a situação da cidade e servir de instrumento para planejar as mudanças necessárias à nova sede da corte, articulando o projeto civilizatório ao território. Juntas indicavam uma nova forma de organização e intervenção, principalmente se atrelados à introdução da décima urbana.

Figura 3: Mapa do Rio de Janeiro requisitado por D. João VI em 1808 e publicado em 1812.

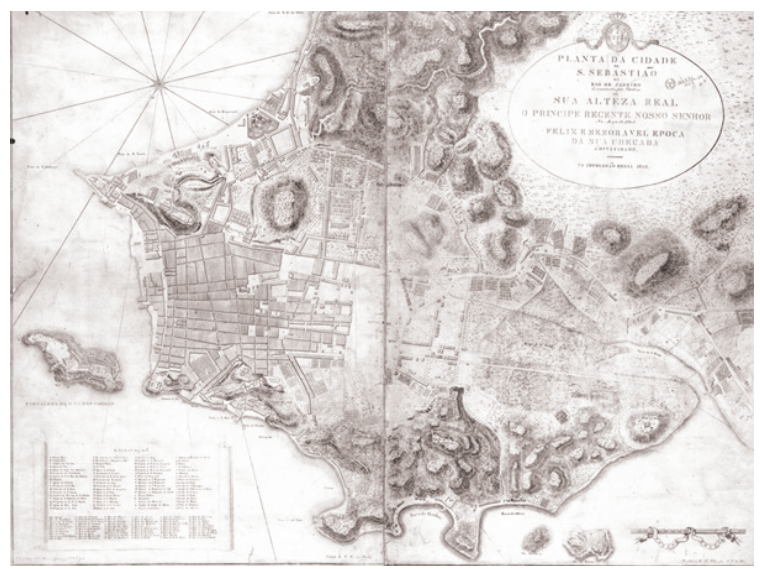

Fonte: Base digital da Biblioteca Nacional. Disponível em: <http://bndigital.bn.br/acervo-digital/>. Acesso em: 16 jul. 2013.
O diagnóstico é produzido, ainda em 1808, pelo médico Manuel Vieira da Silva, físico-mor do reino, encarregado por D. João de investigar as causas da insalubridade da cidade. $O$ fato de ter sido encomendado pelo príncipe e publicado na imprensa transformaria o estudo em orientação oficial. Os objetivos de D. João eram criar uma cultura de discussão na cidade e divulgar um documento que fosse visto como inquestionável. Os médicos eram interlocutores privilegiados para falar dos problemas da estrutura urbana, principalmente por articular a saúde e doença da população ao meio geográfico (SILVA, 2012, p. 61). Essa associação permitiria que o higienismo se tornasse um potente discurso para pensar a cidade durante o século XIX e primeiras décadas do século XX.

\section{Reconstruindo a Corte Portuguesa}

A vinda da família real foi o primeiro momento em que a ideia de civilização começaria a ser articulada ao território da cidade, e todas as mudanças que ocorreriam na estrutura urbana e social naquele período teriam como pano de fundo a sua adaptação à função de sede do Império nos trópicos (SILVA, 2012). Uma nova maneira de se pensar a cidade seria introduzida marcando definitivamente o futuro da cidade do Rio de Janeiro.

A instituição responsável pelo bem público e comum era a Intendência Geral da Polícia, uma das repartições trazidas pela família real. Era responsável pelas obras públicas, abastecimento de água, iluminação e segurança, e ainda pela disciplinarização da vida dos moradores. A provisão e a regulamentação de moradias figuravam entre os empreendimentos mais imediatos com que a Intendência estava envolvida. 
A transformação do Rio de Janeiro em corte real tinha de envolver a marginalização da estética e das práticas que não conseguiam refletir essa mudança. Era consenso entre as classes dominantes que não ser mais colônia significava adotar um projeto colonial: civilizar-se. Para isso eram necessárias a criação e a imposição de uma uniformidade estética e cultural, "no sentido de tornar a cidade em condições de servir de sede às principais autoridades do reino" (BRASIL, 1923, p.11).

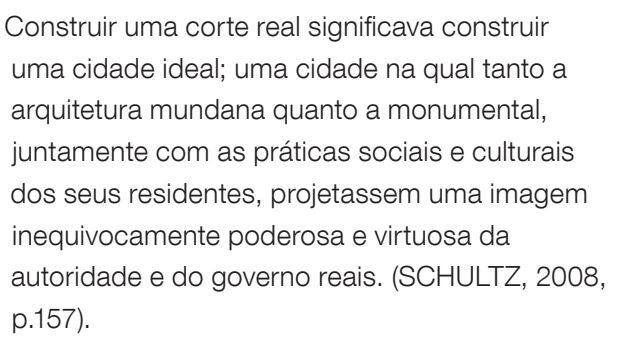

Em março de 1811 Viana propôs que a solução da crise na provisão de habitações na já apertada Cidade Velha podia ser encontrada se a atenção fosse centrada numa região fora do centro da cidade conhecida como Cidade Nova, onde os pântanos cobriam a maior parte de área. Os residentes deveriam ser estimulados a secar $e$ aterrar a área e construir casas. Assim, a cidade seria enobrecida, mais habitações estariam à disposição, e os aluguéis cairiam. A imposição de padrões para a construção na área poderia ser disfarçada por meio de isenções. Mais importante, "as intervenções da coroa dariam fim à 'liberdade mal entendida' de construir como quiser, reforçando conseqüentemente a autoridade do príncipe regente" (SCHULTZ, 2008, p.163).

Ficou estabelecido então que seria concedida isenção da décima urbana por dez ou vinte anos aos proprietários que edificassem casas de sobrado nos terrenos situados na Cidade Nova; a construção de casas de um só pavimento ficava proibida.

\section{A Missão Artística Francesa}

Com o objetivo de modernizar e se afastar dos traços coloniais da cidade, novos padrões de civilidade são importados da França e Inglaterra, influenciados pela razão da elite burguesa e da Revolução Industrial, trazidos pela Missão Artística Francesa em 1816. De caráter civilizatório e chefiado por Joaquim Lebreton, o projeto trouxe consigo uma nova ideologia de arquitetura, artes e espaço urbano, e tinha como objetivo principal atualizar o gosto e a técnica do império em território brasileiro.

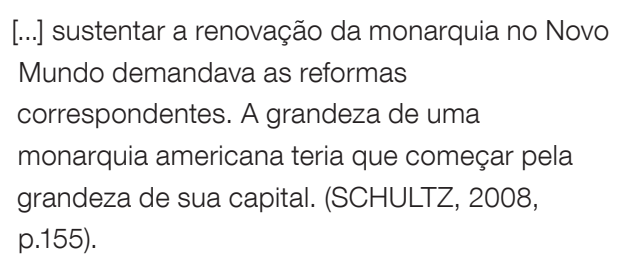

Para Schwarcz (2008) a chamada Missão Artística Francesa foi uma grande convergência de interesses. A autora defende que, diferentemente da versão oficial, a iniciativa e realização do projeto partiu dos artistas franceses, encabeçados por Joaquim Lebreton, tendo o governo português apoiado o grupo após sua chegada em terras brasileiras. Somente décadas depois seria denominada como "Missão Francesa".

De um lado estava uma série de artistas franceses formados pela Academia de Artes Francesa, no mais estrito estilo neoclássico, vinculados ao derrotado Estado Napoleônico. Desempregados, perderam boa parte de suas economias.

Do outro, D. João VI recebeu com muito bom grado a proposta dos artistas. A corte tinha bastante interesse em recepcionar um grupo de acadêmicos que poderiam reformular e elevar sua representação oficial. Em uma sociedade majoritariamente analfabeta, a iconografia se apresenta como importante instrumento para construção e fortalecimento da pátria local.

O arquiteto projetou a decoração de inúmeros festejos públicos, algumas eram efêmeras, outras não. O fato é que todas tinham como objetivo afirmar a superioridade e a presença da Corte diante das camadas mais populares. Segundo Telles (2000), essa arquitetura do espetáculo, que afirmava o neoclássico como o estilo do império, tinha também como objetivo transmitir a ilusão de se estar em uma capital europeia, desvinculando assim a cidade de seu passado colonial.

O primeiro dos seus grandes projetos urbanísticos estava vinculado à construção de um novo palácio imperial e reorganização do centro do Rio de Janeiro. Por volta de 1826, Montigny elabora o projeto de uma extensa avenida monumental que permitiria a ligação entre o Campo de Santana, o Largo do Rocio e a Praça XV, a qual abrigaria o novo palácio, incorporando o Paço Real à nova estrutura.

Em 1827 uma elaborada proposta prevê a preparação de uma nova malha urbana no mangue de São Diogo, da Cidade Nova, mais regular e simétrica, além da remodelação do Campo de Santana, circundado de edifícios políticos e administrativos, conforme uma praça francesa, 
revelando assim a intenção de criar um novo centro de poder afastado do núcleo colonial - a partir dele toda urbe seria reorganizada.

De acordo com Taunay (1956), pode-se afirmar que Grandjean foi o primeiro grande urbanista que teve o Rio de Janeiro e o primeiro técnico do Brasil, fora da área da saúde, que se preocupou com a higiene dos edifícios. O problema do saneamento e da drenagem, questões fundamentais que só seriam resolvidas muito mais tarde, são preocupações do arquiteto em seus projetos, quando prevê linhas para saída das águas e dos esgotos.

O projeto neoclássico para a cidade não se realiza. Apesar do sucesso obtido nas exposições públicas da Academia, a maioria dos seus projetos é destinada a ficar no papel. Do plano de Grandjean só ficam alguns edifícios isolados e algumas ideias urbanísticas separadas do contexto em que tinham sido elaboradas. A abertura da monumental avenida retilínea, que corta a trama da cidade velha, será realizada no início do século $X X$, por ocasião da radical

Figura 4: Plano de parte da cidade do Rio de Janeiro situando novo Palácio Imperial.

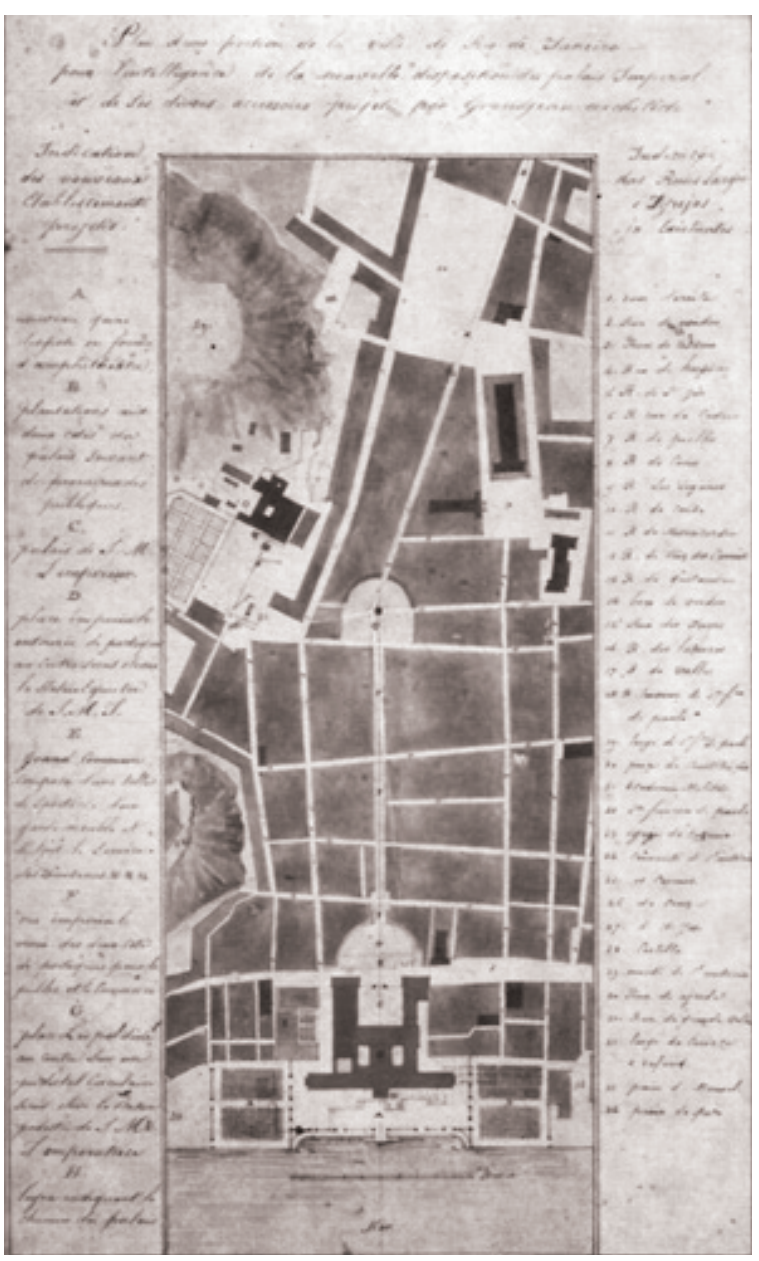

Fonte: PUC-RJ, 1979, p. 161 "modernização" da cidade executada pelo prefeito Pereira Passos.

Entre 1808 e 1821 a população dobrou, passando de cerca 50 a 60 mil habitantes para 100 a 120 mil (RIO DE JANEIRO, 2008). A presença do rei no Rio de Janeiro exercia atração sobre os habitantes de outras partes do Brasil, das Américas e da própria Europa. Gomes (2007) afirma que os treze anos em que a Corte portuguesa permaneceu no Brasil não se comparam com nenhum outro período da história brasileira no que diz respeito às profundas, decisivas e aceleradas mudanças.

As transformações pela qual a cidade passaria deveriam dar conta desta nova exigência, ao fazer convergir todas as atenções para o Rio, agora sede da Coroa para torná-la cabeça do Brasil. No entanto, é necessário falar em perdas e ganhos nesse processo de metropolização, pois as mesmas transformações que aproximavam a cidade dos atributos europeus, tornando-a mais limpa, iluminada, com teatros e modas cortesãs, afastavam-na de suas características coloniais, a exemplo da proibição do uso de rótulas em prédios residenciais (SCHULTZ, 2008; SILVA, 2012).

\section{As transformações do Rio de Janeiro pós-Independência}

Duas décadas após o retorno de D. João VI a Portugal em 1821 e o rompimento com a Corte portuguesa em 1822, o contexto social e urbano do Rio de Janeiro era de grande crescimento demográfico. Esse incremento da população urbana não foi, no entanto, acompanhado de proporcional melhoria nas condições de higiene. Logo, não é de se surpreender que os problemas sanitários tivessem destaque no planejamento urbanístico desde essa época.

Apesar de pouco conhecido, o Relatório Beaurepaire, formulado pelo então diretor de Obras Municipais, pode ser considerado o primeiro plano urbanístico para a cidade do Rio de Janeiro, por apresentar uma proposta global de organização formal. O relatório, não se restringindo aos problemas emergenciais, fez uma extensa avaliação dos problemas da cidade e sugeriu algumas medidas para resolvê-los.

A ânsia por melhoria e embelezamento da cidade, que teve como uma das primeiras consequências as propostas da Missão Francesa, alcançou sua maturidade no início da década de 1840, quando a elite do império e o Conselho de Estado começaram a demonstrar interesse pela 
realização de melhorias, associadas também à consolidação da burguesia urbana (ANDREATTA, 2006). Além disso, podemos destacar o sucesso econômico do plantio de café, que equilibrou as contas externas do país, permitindo a formação de capital nacional que, em conjunto com o capital estrangeiro, estimularam o progresso e desenvolvimento.

Henrique Beaurepaire-Rohan, após alguns anos viajando pelo território brasileiro como membro do Imperial Corpo de Engenheiros, retornou e encontrou a cidade com os mesmos problemas que existam anteriormente. Deficiente captação e distribuição de águas, falta de calçamento das ruas e iluminação pública continuavam ocupando todo o orçamento da Inspetoria de Obras Públicas do Ministério dos Negócios do Império. Cedido à Câmara Municipal da Corte entre 1842 e 1843, confeccionou o relatório que se tornaria referência para pensar a cidade nos anos seguintes.

Seu relatório é dividido em duas partes: salubridade pública e aformoseamento da cidade. As principais propostas da primeira parte, utilizando critérios higienistas, são: a transferência do matadouro público para a praia de São Cristóvão; a solução para a questão do esgotamento sanitário através da adoção do padrão europeu; construção de encanamentos para abastecimento de água por todas as casas a partir dos rios Carioca e Maracanã; estabelecimento de um canal de navegação no mangue da Cidade Nova - Canal do Mangue - com o objetivo de eliminar o grande "foco de miasmas" da região; desmonte do Morro do Castelo a fim de ampliar a extensão da cidade e contribuir para salubridade e embelezamento.

Figura 5: Esquema parcial das propostas do Plano Beaurepaire realizado sobre a planta de 1854

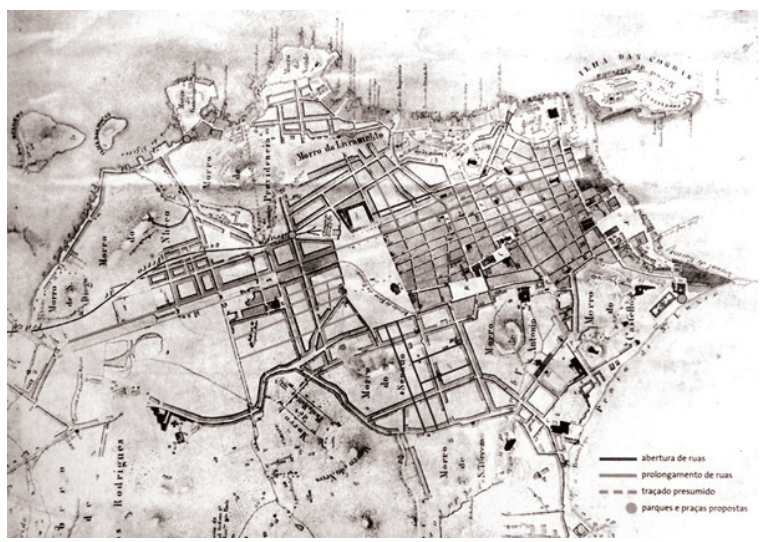

Fonte: Rio de Janeiro, 2008, p. 29
Sobre as propostas de aformoseamento, utilizando critérios urbanísticos e estéticos, Beaurepaire dedica um plano de reedificação à região considerada mais "defeituosa", a Cidade Velha. Visando melhorar a circulação, propõe ampliação e abertura de diversas vias estabelecendo alguns critérios urbanísticos, como extensão dos quarteirões e altura das edificações. Reitera ainda a necessidade de caimento adequado das calçadas, favorecendo o esgotamento. Sobre as praças, além de recomendar a abertura de oito novas em locais específicos, propõe a regularização da Praça da Aclamação. Para isso recorre à parte da antiga proposta de Grandjean de Montigny que, apesar de não ter sido colocada em prática, é recuperada no Plano Beaurepaire, sofrendo adaptações.

A Secretaria Municipal de Urbanismo (RIO DE JANEIRO, 2008) destaca a atualidade de suas propostas, assinalando que, se muitas daquelas sugestões tivessem sido realizadas naquele momento, inúmeras questões atuais da cidade seriam minimizadas. $\mathrm{O}$ fato é que mesmo o plano não tendo sido colocado em prática levantou importantes questões, estimulando a discussão urbanística e abrindo portas para que, algumas décadas mais tarde, a Comissão de Melhoramentos fizesse uma nova proposta.

\section{O Rio de Janeiro e o processo de modernização}

No que tange à infraestrutura, após séculos tendo seu esgoto despejado a céu aberto em valas ou mesmo nas praias, o quadro sanitário da cidade foi se agravando, tornando-se o principal alvo da campanha movida pelos médicos e, logo depois, pela opinião pública, a favor de melhorias que saneassem a capital do império.

O serviço foi entregue à companhia inglesa The Rio de Janeiro City Improvements. Apesar de ser quantitativamente eficaz, o serviço prestado sempre foi criticado como de má qualidade.

A classe proletária, com reduzido ou nenhum poder de mobilidade, adensava-se cada vez mais nas freguesias urbanas centrais. O capital, sobretudo estrangeiro, à sombra dos privilégios concedidos pelo Estado Imperial, apossou-se de grandes fatias do urbano, penetrou em muitas esferas básicas para a existência cotidiana de uma população cada vez mais numerosa, concentrada nos exíguos limites da área central do Rio de Janeiro (BENCHIMOL, 1992). Um contingente cada vez mais numeroso de trabalhadores livres trabalhava e habitava essa mesma região. 
O Rio sempre foi considerada uma cidade insalubre, mas registros indicam que a primeira grande epidemia de febre amarela tenha sido em 1850. A formação da Comissão Central de Saúde Pública e outras medidas que se sucederam marcaram a institucionalização de um tipo de medicina que vinha se constituindo desde os anos de 1830-1940.

A medicina social contribuiu decisivamente para a promulgação das primeiras leis submetendo a normas e interdições o crescimento "espontâneo" da cidade. Tais leis foram quase sempre ineficazes, no entanto seu discurso se infiltrou no senso comum das camadas dominantes e das camadas médias, culturalmente subalternas, que nos anos 1870 já construíram uma influente "opinião pública" favorável a todo tipo de melhoramento que transformasse a capital do império numa metrópole salubre e moderna.

O segundo quartel do século XIX marcou o início da difusão dos transportes ferroviários por todo o mundo. A separação dos usos e classes que se amontoavam no antigo espaço colonial só foi possível com a introdução do bonde de burro e do trem a vapor, que se constituíram nos grandes impulsionadores do crescimento físico da cidade.

Nesse contexto de grandes transformações, as contradições sociais se tornaram ainda mais evidentes, aguçadas pelas fortes epidemias de febre amarela. O então ministro do Império propôs ao Imperador, em 1874, a nomeação de uma Comissão de Melhoramentos da cidade do Rio de Janeiro, composta pelos engenheiros Francisco Pereira Passos, Jerônimo Rodrigues de Morais Jardim e Marcelino Ramos da Silva. Dois relatórios foram apresentados, um em 1875 e outro em 1876, considerado o primeiro plano urbanístico da cidade a ser levado ao conhecimento público, ampliando as discussões acerca do urbano.

O primeiro relatório é apresentado ainda em 1875, apenas dez meses após a nomeação da comissão, e concentra suas propostas na área da Cidade Nova. Os engenheiros justificavam a escolha afirmando que aquela seria a região mais necessitada de melhoramentos, que oferece melhor condições para o desenvolvimento da cidade e na qual os gastos e dificuldades para as obras seriam menores.

A comissão elege o Canal do Mangue como eixo principal das propostas nesse primeiro relatório. Este deveria ser navegável e ajudar a solucionar a questão do dessecamento das áreas pantanosas, que ainda eram um obstáculo para a expansão urbana. Para isso, seu prolongamento até o mar e a canalização dos rios eram primordiais.

Sobre os parâmetros construtivos, destaca-se, principalmente, a limitação da altura das fachadas e definição de altura mínima de três metros para compartimentos habitáveis. Para as novas grandes avenidas a serem abertas a comissão procura manter o traçado retilíneo e adota padrões de proporção entre a largura da via, calçada e passeios. Fazia parte do esquema viário que essas avenidas formassem grandes eixos monumentais unindo espaços simbólicos, remetendo ao plano de Haussmann para Paris.

Diante de inúmeras críticas por não abarcar a Cidade Velha em seu plano, a comissão apresenta um segundo relatório, em 1876. Possui semelhanças com as ideias do primeiro relatório, insistindo na defesa de suas premissas através de exemplos internacionais. No entanto, dessa vez os engenheiros também se debruçam sobre a Cidade Velha, entendendo como complemento indispensável (ANDREATTA, 2006).

Além de reforçar as propostas contidas no primeiro relatório, a comissão propõe a abertura, prolongamento, alargamento e retificação de uma série de ruas na Cidade Velha. Ratifica os pareceres higienistas e recupera Beaurepaire, ao propor o arrasamento dos Morros de Santo Antonio, Castelo e Senado, afirmando que seria determinante para melhorar a ventilação na cidade. As vultosas demolições e desapropriações necessárias para sua realização também recuperam o Plano Beaurepaire.

Somente uma pequena parcela das propostas começou a ser colocada em prática

Figura 6: Síntese das propostas da Comissão de Melhoramentos sobre a planta geral da cidade de 1875 .

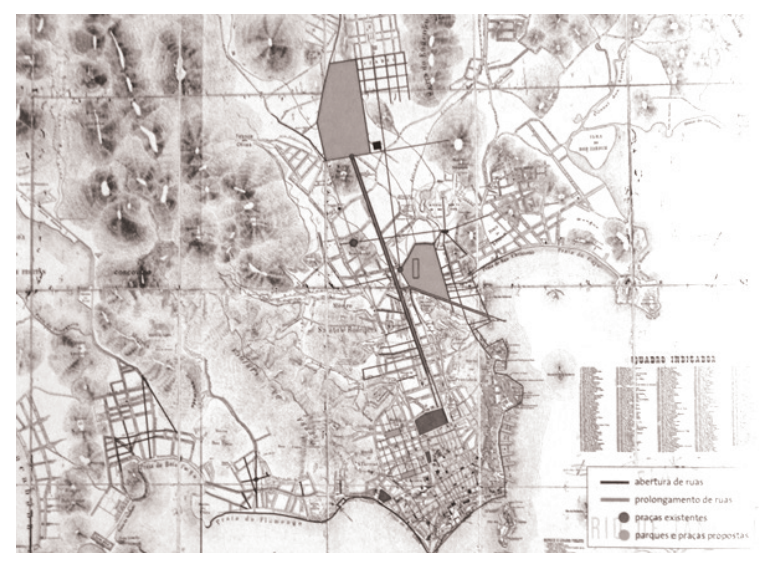

Fonte: Rio de Janeiro, 2008, p. 60. 
principalmente por problemas financeiros. No entanto, além de levantar a questão urbanística para discussão pública, a Comissão de Melhoramentos foi fundamental para moldar o pensamento daquele que viria a ser prefeito da cidade do Rio de Janeiro alguns anos mais tarde. Francisco Pereira Passos era um dos engenheiros responsáveis pelo plano, e pôde colocar em prática boa parte no início do século XX, naquela que é considerada a primeira intervenção sistemática e direta do Estado sobre o espaço urbano carioca.

\section{Primeiras intervenções no século $X X$}

A cidade entra no século $X X$ como república desde 1889 e com uma série de problemas urbanísticos. Visando difundir no território urbano a ideia de modernidade e baseando-se em experiências de capitais europeias, a classe política republicana busca a construção de uma imagem simbólica da cidade vinculada ao seu papel de centro da nação. Para tanto seus espaços devem ser ampliados, ordenados e embelezados.

O grande realizador dessa missão foi Pereira Passos, que ganhou plenos poderes do então presidente Rodrigues Alves, cujas ações tiveram enfoque na capital da República. Fundamentado em muitos dos argumentos utilizados nos planos já apresentados, um Pereira Passos mais maduro propõe a abertura de sete eixos viários que seriam suporte da cidade remodelada.

A monumentalização da cidade foi reforçada, pessoas foram expulsas do Centro, tanto pela derrubada de prédios e do Morro do Senado quanto pela valorização dos terrenos, sendo um dos fatores que levaram ao aparecimento das primeiras favelas, além de deixar uma imensa dívida pública para seus sucessores. A eficiência na execução imediata e na programação das obras difere esse plano dos anteriores, e faz com que seja tão comentado e estudado, um verdadeiro marco na história do Rio de Janeiro.

O "bota-abaixo" dos primeiros anos do século $X X$ recupera uma série de novas maneiras de se pensar a cidade que se desenvolveram a partir da transferência da Corte portuguesa, quando passou a ser planejada e modificada para se aproximar à grandeza de uma capital europeia, quando novas classes e novos usos passaram a conviver na apertada cidade colonial. Afastandose dos traços coloniais, os planos do século anterior buscaram principalmente monumentalidade, embelezamento, saneamento, visando tornar o Rio de Janeiro o centro da nação, um modelo de cidade nacional.

Através da recuperação do discurso higienista, Pereira Passos promove a abertura e alargamento de uma série de eixos monumentais, que transformariam a imagem do Rio de Janeiro. $\mathrm{O}$ grande marco é a Av. Central, que "rasgou" de mar a mar a cidade velha com 1.800 metros de comprimento e 33 metros de largura, demolindo cerca de 700 edificações, entre elas cortiços e outras habitações das classes populares, que seriam, segundo o prefeito, as principais fontes de insalubridade da cidade. Um concurso de fachadas em estilo neoclássico foi promovido para que a nova via se aproximasse ainda mais do padrão europeu. A canalização do mangue na Cidade Nova em conjunto com a construção de uma larga avenida, premissa na proposta da Comissão de Melhoramentos, é finalmente concretizada.

Outras propostas que nasceram no século XIX, como a derrubada do Morro do Castelo e do Morro de Santo Antonio, só foram colocadas em

Figura 7: Detalhe do projeto de abertura da Av. Central. Em cinza a nova via a ser aberta, promovendo vultosa demolição do casario antigo.

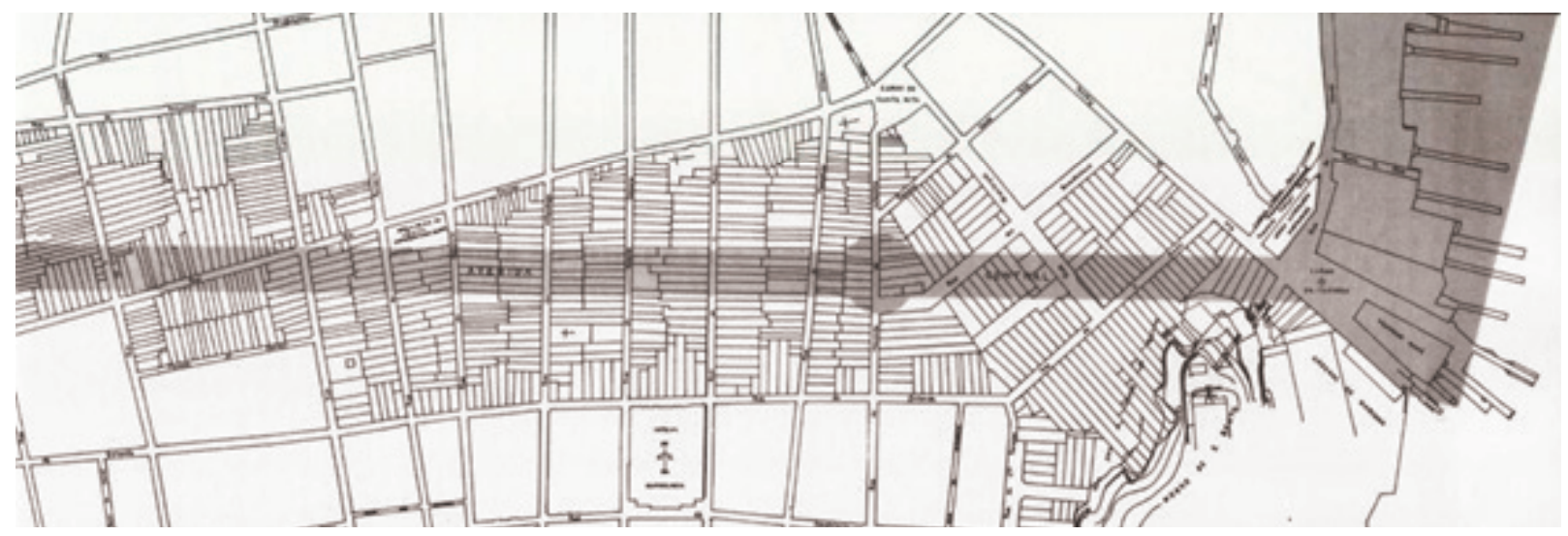

Fonte: Abreu, 2008, p. 65. 
prática algumas décadas depois, em 1921 e 1950, respectivamente, o que mostra por quanto tempo as ideias difundidas naquele século permaneceram vivos e o quão importante foi sua influência.

\section{Referências}

ABREU, M. de A. A evolução urbana no Rio de Janeiro. Rio de Janeiro: IPP, 2008.

ANDREATTA, V. Cidades quadradas, paraísos circulares: os planos urbanísticos do Rio de Janeiro no século XIX. Rio de Janeiro: Mauad X, 2006.

BENCHIMOL, J. L. Pereira Passos: um Haussmann tropical. Transformações urbanas na cidade do Rio de Janeiro no século XX. Rio de Janeiro: SMCTE/DGDIC, 1992.

BRASIL. Ministério da Agricultura, Indústria e Comércio. Recenseamento do Brazil: população do Rio de Janeiro. v. II. Rio de Janeiro, 1923.

PINTO, F. M. A invenção da cidade nova do Rio de Janeiro: agentes, personagens e planos. 2007. Dissertação (Mestrado) - Universidade Federal do Rio de Janeiro, Rio de Janeiro, 2007.

PUC-RJ. Pontifícia Universidade Católica do Rio de Janeiro. Departamento de Artes. Uma cidade em questão: Grandjean de Montigny e o Rio de Janeiro. v. 1. Rio de Janeiro: PUC: Funarte: Fundação Roberto Marinho, 1979.

RIO DE JANEIRO. Prefeitura. Dicionário do Brasil Joanino: 1808-1821. Org. Ronaldo Vainfas e Lucia Bastos Pereira das Neves. Rio de Janeiro: Objetiva, 2008.

SCHULTZ, K. Versalhes tropical: império, monarquia e a Corte real Portuguesa no Rio de Janeiro, 1808-1821. Trad. Renato Aguiar. Rio de Janeiro: Civilização Brasileira, 2008.

SCHWARCZ, L. M. O sol do Brasil: NicolasAntonie Taunay e as desventuras dos artistas franceses na corte de D. João. São Paulo: Companhia das Letras, 2008.

RIO DE JANEIRO. Secretaria Municipal de Urbanismo. Planos urbanos: Rio de Janeiro, o século XIX. Coord. Maria de Carvalho Elias Rabha. Rio de Janeiro: IPP, 2008.

SILVA, L. Memórias do urbanismo na cidade do Rio de Janeiro 1778/1878: Estado, administração e práticas de poder. Rio de Janeiro, 2012.
TAUNAY, A. de E. A missão artística de 1816. Rio de Janeiro: Ministério da Educação e Cultura/IPHAN, 1956. 